\title{
Mutual Fund Ratings and Performance Persistence*
}

\author{
Pierre Hereil \\ Research \& Development \\ Lyxor Asset Management, Paris \\ pierre.hereil@lyxor.com \\ Nicolas Moussavi \\ Research \& Development \\ Lyxor Asset Management, Paris \\ nicolas.moussavi@lyxor. com
}

\author{
Philippe Mitaine \\ Research \& Development \\ Lyxor Asset Management, Paris \\ philippe.mitaine@lyxor.com \\ Thierry Roncalli \\ Research \& Development \\ Lyxor Asset Management, Paris \\ thierry.roncalli@lyxor.com
}

\section{June 2010}

\begin{abstract}
This paper studies the persistence of mutual fund performance. Academic research often focuses on fund returns, sometimes adjusted for style and market cap biases. Because fund rating systems play a central role in the asset management industry, we consider another approach in this paper. Using a Markov modeling of these ratings, we illustrate that the persistence of the performance is relatively poor with respect to the time horizon of investors. We show that two facts may explain these results. First, the rating system is not necessarily time-homogeneous. Second, the importance of style is crucial when comparing the ratings of mutual funds. However, we show that it is extremely difficult to characterize quantitatively the style of a mutual fund. We conclude that fund selection is more art than science, and that quantitative analysis must be combined with qualitative insight.
\end{abstract}

Keywords: Mutual funds, rating system, style analysis, Markov chain, active management.

JEL classification: G11, G24, C53.

\section{Introduction}

The academic literature on mutual fund performance is large, which is not surprising. The Investment Company Institute records a total of 69,032 mutual funds at the end of 2008, and assesses that mutual funds manage worldwide more than USD 22 trillion in the third quarter 2009, including more than one third in equity mutual funds ${ }^{1}$.

The question of how investors select mutual funds is not new and dates back to Treynor (1965). Even if their behaviors are very different, they tend to use the same tools, generally based on a fund rating system. Among the several fund rating agencies, Morningstar is a

\footnotetext{
*We are grateful to Serge Darolles, Nicolas Gaussel, Abdul Koudiraty and Corinne Parlier for their helpful comments.

${ }^{1}$ Source: http://www.icifactbook.org/.
} 
leading company providing mutual fund information. Since 1985, mutual funds are ranked according to the famous Morningstar stars. These ratings are quantitative and are based on past performance. Even if the usual disclaimer "past performance is no guarantee of future results" is relevant, these stars are often used by investors in a prospective way. However, we may wonder if these ratings are robust enough to draw some conclusions from an investment point of view.

The academic research on mutual fund performance generally investigates the dynamics of their returns. Many studies agree that mutual funds underperform passive benchmarks by a statistically and economically significant margin. Results on the persistence of performance are more diverse. For a long time, most academic studies concluded that the performance of a mutual fund is persistent over a time horizon of three years. However, this conclusion has been significantly challenged by the work of Carhart (1997) who, by using a momentum factor, did not find a strong persistence of the performance. This point of view is generally supported by some recent studies, while others continue to demonstrate a short-term persistence of the performance. Several studies also point out that portfolio manager skills cannot be inferred from past performance. Another issue tackled by the literature is the influence of several factors on performance, like for example the fund size or the portfolio concentration. Thus, it appears that past performance and ratings cannot be the only criteria to be considered from an investment point of view.

The paper is organized as follows. Section two presents a survey on the existing literature about the performance persistence of mutual funds based on historical returns. In section three, another approach based on Markov modeling of fund rating systems is considered. In section four, we highlight that stock or bond picking is not the only contributor to the fund's performance. Thus, an important part of the performance may be explained by the style bias. Our results on the persistence of fund rating systems may be analyzed with regard to this style bias. Section five offers some concluding remarks.

\section{Academic research on mutual fund performance}

In this section, we consider the large academic research on the performance persistence of mutual funds. Equity funds are studied in the first paragraph, whereas the second paragraph presents the case of bond funds. In the last paragraph, we consider the characteristics that may influence the performance of mutual funds, including fund size, inflows and outflows, fees, etc.

\subsection{Persistence of equity mutual funds}

Investors generally rely on managers past risk-adjusted performance in order to assess their ability to generate excess returns. It is then important to evaluate whether or not past performance has predictive value regarding future performance. In other words, we would like to know if the past winners are the future winners. We focus here on studies performed on US equity funds, because they constitute the widest area of research on this subject ${ }^{2}$.

\footnotetext{
${ }^{2}$ Performances of UK mutual funds are studied in some papers. They lead to similar conclusions - Allen and Tan (1999), Fletcher and Forbes (2002).
} 


\subsubsection{Early studies}

The first studies on mutual fund performance were already contradictory. Sharpe (1966) uses the Sharpe ratio to measure fund performance. He ranks the funds over two periods 19441953 and 1954-1963, and finds a positive relationship between these two ranking periods. On the contrary, Jensen (1968) measures the performance of 115 mutual funds in the 19451964 period using the Jensen alpha measure, and shows that they do not outperform on average a buy-and-hold strategy. He concludes also that "there is very little evidence that any individual fund was able to do significantly better than that which we expected from mere random chance".

The first studies in the eighties based on Jensen alpha ${ }^{3}$ conclude on the persistence of performance on US equity funds (Lehmann and Modest (1987), Grinblatt and Titman (1989)). Grinblatt and Titman (1992) study US equity funds between 1974 and 1984. They consider two periods of five years and estimate the alpha of each fund over these two periods. They then perform a cross-section regression between the alpha of these two periods and find predictability in past winner and past looser deciles. They finally deduce:

"The results presented in this paper indicate that there is positive persistence in mutual fund performance [...] we can assert that the past performance of a fund provides useful information for investors who are considering an investment in mutual funds".

Using the same period, Hendricks et al. (1993) use a contingency table approach on raw returns and alphas. They conclude on the predictability for growth-style funds over successive one-year periods. Goetzmann and Ibbotson (1994) also find evidence of predictability at time horizons from one month to three years.

Even if the early studies take into account the presence of survivorship ${ }^{4}$ and style biases, these two problems are addressed by recent studies in a more satisfactory way. In particular, they focus extensively on factor modeling to correctly measure the alpha.

\subsubsection{Recent studies}

Following the works of Fama and French ${ }^{5}$, Elton et al. (1996a) measure the alpha of US mutual funds with a four-factor model. The factors are a global market factor, a small cap factor, a style factor ${ }^{6}$ and a bond factor. The main lesson that can be learned from this study is that "both one and three-year alphas convey information about future performance". Brown and Goetzmann (1995) find similar results on average, but notice that these results depend on the time period of analysis. Grinblatt et al. (1995) remark that mutual funds have a tendency to buy stocks based on their past returns and that funds following momentum strategies obtain significant excess performance while contrarian funds do not present any alpha. This suggests that the positive results observed in previous studies may be a simple trading rule rather than better stock picking skills. In a key paper, Carhart (1997) uses a different four-factor model, adding a one-year momentum factor to the Fama-French threefactor model. Over the years, this model has become a standard model in most studies

\footnotetext{
${ }^{3}$ The Jensen alpha will be defined in paragraph 4.1. In the rest of the paper, we use the term alpha in place of Jensen alpha.

${ }^{4}$ The survivorship bias is the difference between the performance of survivor funds and the performance of the combined set of survivor and dead funds. It is well documented in the academic literature (see for example Elton et al. (1996b), Blake and Timmermann (1998) or Kosowski et al. (2006)) and may be very large. Thus, Malkiel (1995) reports a survivorship bias of $1.4 \%$ per year on US equity funds for the period 1982-1990.

${ }^{5}$ The Fama-French model is presented on page 14.

${ }^{6}$ It corresponds to the difference of the performance of growth stocks and the performance of value stocks.
} 
on equity funds. Even if there are some results in favor of one-year persistence, there is a fundamental break between the Carhart's conclusion and previous ones:

"I demonstrate that common factors in stock returns and investment expenses almost completely explain persistence in equity mutual funds' mean and riskadjusted returns. Hendricks et al. (1993) "hot hands" result is mostly driven by the one-year momentum effect of Jegadeesh and Titman (1993) [...] The only significant persistence not explained is concentrated in strong underperformance by the worst-return mutual funds. The results do not support the existence of skilled or informed mutual fund portfolio managers".

Some recent studies use more sophisticated statistical analyses ${ }^{7}$. They use bootstrap techniques which allow for non-normality in the idiosyncratic risks of the funds ${ }^{8}$. They consider several models to test persistence and generally use time-varying parameters in their regression models. The underlying idea is that any fixed parameter model may not correctly capture the puzzle of portfolio risks arising from the diverse trading strategies pursued by the universe of mutual funds. Some studies also show that persistence is dependent on the methodology used to rank funds on their past returns. Bollen and Busse (2004) find no persistence when funds are ranked with one-year returns, but they find short-term persistence when funds are ranked with the alpha measure deduced from Carhart's model and computed on a quarterly frequency. Mamaysky et al. (2007) apply different statistical models based on recursive OLS and Kalman filter with time-varying parameters to US mutual funds. They also conclude that there is significant negative (resp. positive) performance for the bottom (resp. higher) deciles. According to Huij et al. (2007) and Budiono and Martens (2009), ignoring time-varying factor exposures leads to overestimating (respectively underestimating) the performance persistence in the Fama-French model (respectively the Carhart model).

Other recent studies address the question whether the performance of the best mutual funds is due to luck or to genuine stock picking. These papers generally conclude that there are very few managers with true stock picking skills. According to Kosowski et al. (2006), there is strong evidence of superior performance and persistence among US growthoriented funds. On the contrary, they do not find any ability among managers of incomeoriented funds. Cuthbertson et al. (2008) use bootstrap techniques to show the existence of genuine stock picking ability for around $5 \%$ to $10 \%$ of UK equity mutual funds. Most of the underperforming funds demonstrate bad skills. Furthermore, when examining fund styles, they find genuine stock picking skills among the top performers in the equity income funds category. On the contrary, there is little evidence of skill among the best performers of the all company funds and the small cap funds. Barras et al. (2010) develop a simple technique to classify funds into skilled and unskilled funds. They exhibit a significant proportion of skilled funds prior to 1996, while this proportion rapidly decreased to an insignificant level of $0.6 \%$ in 2006. This is consistent with the theoretical work of Berk and Green (2004) who show that past performance cannot be used to infer skill level of fund managers.

\subsection{The case of bond mutual funds}

The number of academic studies on bond funds is rather small compared to that of studies on equity funds, even if they represent a very large part of the mutual funds industry. Similarly to results on equity funds, Blake et al. (1993) and Detzler (1999) show that bond funds underperform their benchmarks on average, and they conclude that the underperformance is approximately equal to the management fees.

\footnotetext{
${ }^{7}$ See e.g. Mamaysky et al. (2007).

8 This is a major issue when considering funds which appear to be either very good or very bad performers. And these funds are those which investors are primarily interested in identifying.
} 
Conclusions are less clear regarding the persistence of performance. Blake et al. (1993) do not find any persistence, and suggest that the performance differences between actively managed bond funds can be explained either by differences in the duration or by differences in the credit risk premiums. In a recent study, Huij and Derwall (2008) obtain different results. Using a large universe of about 3,500 bond funds from 1990 to 2003, they measure their performance using a three-factor model ${ }^{9}$. They show that "bond funds that display strong (weak) performance over a past period continue to do so in future periods". The out-of-sample difference in risk-adjusted return between the top and bottom deciles of funds ranked on past alpha exceeds $3.5 \%$. They find that their results are robust to a wide range of model specifications and bootstrapped test statistics.

\subsection{Some related questions}

In this paragraph, we consider the main parameters which can influence the performance of funds: assets under management, concentration, expenses and geographical implantation.

\subsubsection{Do size and flows matter?}

Chevalier and Ellison (1997) look at the influence of net flows on fund performance and show that mutual funds inflows and outflows are strongly related to lagged measures of performance, in spite of the non-persistence of the performance. A mutual fund which has well performed in the past is very attractive for most investors. Inversely, large inflows may influence the fund management. Portfolio liquidity may be affected as well as the fund philosophy. Ciccotello and Grant (1996) explicit the difficulties of large funds managers to move quickly in and out of positions. For Indro et al. (1999) results are more complex. Mutual fund must attain a minimum fund size to achieve sufficient returns. However, when they exceed a critical size, the level of assets under management may have a negative impact on performance. Edelen (1999) finds a negative relationship between underperformance and subscriptions. This is why most asset managers decide to close or limit new inflows ${ }^{10}$ from investors when the fund reaches a critical size. Recent studies support these early results. Chen et al. (2004) find that smaller funds tend to outperform larger funds due to diseconomy of scale. This assumption is verified both before and after fees, and is more evident on funds invested in small and illiquid stocks. On the other hand, large mutual funds have cost advantages over small funds, with more favorable spreads given market positions and trading volumes. They conclude that organization is the main success element for the management of a big size portfolio. According to the theoretical model of Berk and Green (2004), the negative correlation between size and performance of mutual funds is inherent and is due to the relative inelasticity of the skills of active managers.

\subsubsection{Does concentration enhance the performance?}

The relationship between concentration and performance has not been extensively studied. However, buying a concentrated fund or a diversified fund is an important question for investors. Spontaneously, we may think that a concentrated portfolio leads the portfolio manager to express his best bets. Academic literature has generally demonstrated the benefits of a concentrated portfolio over a less-concentrated one. For example, using US mutual funds data from 1984 to 1999, Kacperczyk et al. (2005) split mutual funds in two categories depending on a concentration measure. They show that the category of concentrated funds presents an outperformance of $1.58 \%$ before expenses deduction (and $33 \mathrm{bps)}$ with respect to the category of more diversified funds. They attribute these results to good stock picking

\footnotetext{
${ }^{9}$ The three factors are an investment-grade index, a high-yield index, and a mortgage-bond index.

${ }^{10}$ This practice is known as soft close.
} 
capability and notice that the trades of concentrated portfolios added more value than those of diversified portfolios.

\subsubsection{Do expenses decrease the performance?}

Buying a fund implies paying fees for the professional management. Some funds apply entry fees. The effect on performance is obvious. We can compare it to a formula one race. If competitors and cars have the same abilities but one starts the race three laps before the others, we easily know who should win the race. Some funds are very active and apply high management fees. However, the argument that highly active managers have to be rewarded with higher fees than slightly active managers is not supported by empirical studies. Thus, Elton et al. (1993) find a negative correlation between fund turnover and fund performance (and a strong negative relationship between expense ratios and fund returns).

The economic theory of incentive contracts tells us that mutual funds with high fees must have better performance than mutual funds with low fees, especially in the case of performance fees ${ }^{11}$. These performance fees are generally considered as the most appropriate way of solving agency problems between investors and managers ${ }^{12}$. However, Starks (1997) shows that incentive fees may have a great impact on the behavior of fund managers and suggests that the contract with incentive fees is not the optimal contract. In particular, interim losers increase the risk of their fund more than interim winners (Brown et al., 1996). This stylized fact is confirmed by the study of Elton et al. (2003), who also find that "incentive fee funds take more risk than non-incentive-fee funds on average". In this empirical study, Elton et al. show that funds with incentive fees present a higher alpha than those without incentive fees ${ }^{13}$.

\subsubsection{Are there some geographical specificities?}

Academic literature gives different answers to the question on the utility of local presence for an asset manager. Shukla and van Inwegen (1995) study the performance of 108 US equity funds and 18 UK managers investing in US stocks over the 1981-1993 period. They find that UK mutual funds underperform significantly US domestic funds and suggest informational disadvantages for foreign fund managers. The study of Coval and Moskowitz (2001) concludes that local investors outperform foreign investors, because they have superior access to information on local firms. According to Otten and Bams (2007), there is no evidence of such advantage and they agree with Kang and Stultz (1997) and Grinblatt and Keloharju (2000) that the difference of performance is largely explained by the difference of management style between foreign and domestic managers.

\section{Markov chain modeling of fund ratings}

A fund rating system generally consists in a stars system. Each fund is assigned a rating from one to five stars based on past performance and risk statistics. In practice, fund ratings are used to distinguish best mutual fund performers from worst. Fund ratings have been developed in the spirit of credit ratings, but there are two big differences. A credit rating is a forward-looking measure. It is a measure of the likelihood of default and is not linked

\footnotetext{
${ }^{11}$ In this case, management fees are generally smaller but the outperformance is well rewarded. For mutual funds, the standard is $10 \%$ of the performance over the benchmark. In the hedge funds industry, this standard is generally $20 \%$.

${ }^{12}$ See the survey of Bhattacharya et al. (2008).

${ }^{13}$ However, as explained by Darolles and Gouriéroux (2010), incentive fees may have a positive impact on risk-adjusted performance because the volatility measure is smoothed.
} 
to a statistical measure based on past data. Conversely, a fund rating is a backward-looking measure based on past performance. However, as is usually mentioned in a disclaimer, past performance is no indication of future returns. The second important difference is that credit ratings are absolute measures of default whereas fund ratings are relative measure of performance.

Based on the seminal empirical work of Garnier and Pujol (2007), we study a fund rating system in the context of a homogeneous Markov chain setting. In Garnier and Pujol (2007), the empirical transition matrix of the mutual funds of the equity asset class distributed in France from 2000 to 2005 is considered, using both the S\&P and the Morningstar rating systems. They find that fund ratings have a poor persistence.

"Our analysis based on a probabilistic method for the estimation of transition matrices has produced two observations. Firstly, there is indeed a certain degree of persistence for star ratings, though low and, above all, it tends to disappear rapidly beyond a three-year time span (the historical period for their calculation). [...] The second observation concerns the surprising variation among star-ratings from one month or quarter to another. This is explained by the visible impact of movements into and out of the ratings classifications, with newly rated funds tending to be better rated on average, while the contrary is true for funds exiting the ratings. This rotation thus contributes to downgrading funds already 'starred'." (Garnier and Pujol, 2007).

Below, we consider several asset classes from 2000 to 2009 using the Morningstar system (see Box 1). We estimate the transition probability matrix and then propose a persistence measure of ratings according to this Markov chain framework.

\subsection{Estimating the one-month transition probabilities}

Let us define $\pi_{(n)}\left(s, k_{1} ; t, k_{2}\right)$ as the probability that the rating of the fund $n$ goes from state $\mathcal{R}_{k_{1}}$ at time $s$ to state $\mathcal{R}_{k_{2}}$ at time $t$. We have:

$$
\pi_{(n)}\left(s, k_{1} ; t, k_{2}\right)=\operatorname{Pr}\left\{R_{(n)}(t)=\mathcal{R}_{k_{2}} \mid R_{(n)}(s)=\mathcal{R}_{k_{1}}\right\}
$$

We assume that the Markov chain is homogeneous and we note $\pi(t)$ the transition matrix between date 0 and date $t$. For each fund category, we observe the monthly ratings of $N$ mutual funds distributed in Europe between 2000 and 2009. Using the results in Appendix B.2, we estimate the monthly transition matrix $\pi\left(\frac{1}{12}\right)$ by using maximum likelihood methods.

\subsubsection{The case of equity mutual funds}

Table 1 presents the one-month transition matrix for the European blend equity category. The state NR means that the mutual fund is not rated. This may be the case of a fund which is too recent to be rated or which is dead. The results are read in the following way: a 5 stars mutual fund has a $83.87 \%$ probability to stay 5 stars in the next month; it has a $15.49 \%$ probability to become 4 stars in the next month; etc. By construction, we verify that the probabilities in one row sum to $100 \%$. Because fund ratings are based on three-years rolling historical periods, the probabilities are concentrated in the diagonal and in the main off-diagonals.

Remark 1 The transition matrix is estimated for two other equity categories (US and $\left.E M^{14}\right)$. It is reported in Table 11 and 12 in Appendix A. Results are very similar to those given in Table 1.

\footnotetext{
${ }^{14} \mathrm{EM}$ stands for the Emerging Markets category.
} 


\section{Box 1: The Morningstar rating methodology}

The Morningstar rating system was created in 1985. Each fund is assigned a rating from one to five stars, based on its risk-adjusted performance measure (RAPM) within its category peer group. Let us consider the following utility function:

$$
U(W)=-\frac{W^{-\gamma}}{\gamma}
$$

where $W$ is the investor's wealth and $\gamma>0$ a parameter that describes the intensity of the investor's risk aversion. We denote by $R$ the monthly excess return of the fund over the risk-free rate. The certainty equivalent excess return $R^{\mathrm{CE}}$ is defined as follows:

$$
U\left(1+R^{\mathrm{CE}}\right)=\mathbb{E}[U(1+R)]
$$

Solving the previous equation gives us:

$$
R^{\mathrm{CE}}=\mathbb{E}\left[(1+R)^{-\gamma}\right]^{-\frac{1}{\gamma}}-1
$$

In order to illustrate that $R^{\mathrm{CE}}$ is effectively a risk-adjusted performance measure, we consider a Taylor expansion of the previous equation:

$$
R^{\mathrm{CE}} \simeq \mathbb{E}[R]-\gamma(\gamma+1) \mathbb{E}\left[R^{2}\right]+\ldots
$$

We verify that $R^{\mathrm{CE}}$ is an increasing function of the mean, but a decreasing function of the volatility. The risk-adjusted performance measure, called the Morningstar risk-adjusted return (MRAR), is then the estimate of the certainty equivalent excess return $R^{\mathrm{CE}}$ :

$$
\operatorname{MRAR}=\left[\frac{1}{T} \sum_{t=1}^{T}\left(1+R_{t}\right)^{-\gamma}\right]^{-\frac{12}{\gamma}}-1
$$

where $T$ is the number of observations and $R_{t}$ is the excess return of the fund at month $t$. In practice, $\gamma$ is set to 2 . The fund is then ranked within its category peer group and a rating is assigned using a percentile rule. The breakdown of stars is as follows: the top $10 \%$ funds are five stars, the next $22.5 \%$ funds are four stars, the next $35 \%$ funds are 3 stars, the next $22.5 \%$ funds are 2 stars and the bottom $10 \%$ funds are 1 star.

Table 1: Estimated one-month transition matrix for Europe blend equity

\begin{tabular}{c|cccccc}
\hline & NR & $\star$ & $\star \star$ & $\star \star \star$ & $\star \star \star \star$ & $\star \star \star \star \star$ \\
\hline $\mathrm{NR}$ & 97.72 & 0.15 & 0.45 & 0.79 & 0.56 & 0.33 \\
$\star$ & 0.57 & 84.61 & 14.08 & 0.57 & 0.10 & 0.05 \\
$\star \star$ & 0.28 & 4.46 & 80.26 & 14.73 & 0.24 & 0.03 \\
$\star \star \star$ & 0.19 & 0.12 & 8.40 & 83.34 & 7.82 & 0.12 \\
$\star \star \star \star$ & 0.17 & 0.03 & 0.33 & 11.92 & 81.89 & 5.66 \\
$\star \star \star \star \star$ & 0.17 & 0.07 & 0.03 & 0.37 & 15.49 & 83.87
\end{tabular}


Using the estimated one month transition matrix, we may compute the transition probabilities for other time horizons. Results for one year and two years are reported in Table 2 and 3 . We notice that the probability to stay in the initial rating is particularly small.

Table 2: One-year transition probabilities for Europe blend equity

\begin{tabular}{c|cccccc}
\hline & $\mathrm{NR}$ & $\star$ & $\star \star$ & $\star \star \star$ & $\star \star \star \star$ & $\star \star \star \star \star$ \\
\hline $\mathrm{NR}$ & 76.11 & 1.53 & 4.81 & 8.65 & 6.16 & 2.74 \\
$\star$ & 4.16 & 20.05 & 31.46 & 30.97 & 11.00 & 2.35 \\
$\star \star$ & 2.80 & 9.94 & 27.57 & 38.31 & 17.19 & 4.20 \\
$\star \star \star$ & 2.23 & 5.55 & 21.77 & 40.12 & 23.37 & 6.96 \\
$\star \star \star \star$ & 1.99 & 2.98 & 14.83 & 35.54 & 31.54 & 13.12 \\
$\star \star \star \star \star$ & 1.89 & 1.75 & 9.83 & 28.89 & 35.89 & 21.76
\end{tabular}

Table 3: Two-year transition probabilities for Europe blend equity

\begin{tabular}{c|cccccc}
\hline & NR & $\star$ & $\star \star$ & $\star \star \star$ & $\star \star \star \star$ & $\star \star \star \star \star$ \\
\hline $\mathrm{NR}$ & 58.49 & 2.66 & 8.54 & 15.35 & 10.63 & 4.33 \\
$\star$ & 5.84 & 9.30 & 23.79 & 35.64 & 19.42 & 6.02 \\
$\star \star$ & 4.59 & 7.49 & 22.16 & 36.57 & 21.88 & 7.30 \\
$\star \star \star$ & 4.03 & 6.36 & 20.74 & 36.66 & 23.73 & 8.48 \\
$\star \star \star \star$ & 3.72 & 5.25 & 18.83 & 36.03 & 25.96 & 10.21 \\
$\star \star \star \star \star$ & 3.55 & 4.41 & 17.10 & 35.10 & 27.88 & 11.96
\end{tabular}

While the transition matrix gives us the information for all states, we are particularly interested in the 5 stars. Consider a fund $n$ which is today 5 stars. The associated survival function to stay $5 \operatorname{stars}^{15}$ is defined by ${ }^{16}$ :

$$
S(t)=\operatorname{Pr}\left\{R_{(n)}(t)=\mathcal{R}_{6} \mid R_{(n)}(0)=\mathcal{R}_{6}\right\}
$$

We have reported the values of $S(t)$ in Table 4 . If we compare the three equity asset classes, we remark that we obtain very similar results. The probability to stay 5 stars is about $85 \%$ the next month, $60 \%$ the next three months, $40 \%$ the next six months, etc. One year later, the probability to stay 5 stars is less than $25 \%$.

\subsubsection{The case of bond mutual funds}

Let us now consider the case of the bond asset class. We consider three categories: bond Euro diversified, bond USD diversified and bond US high yield. The results for bond Euro diversified are given in Table 5 whereas we report the results for the two other bond categories in Tables 13 and 14 in Appendix A. A comparison of these results with those obtained with the equity asset class shows that they are very close. In Table 6 , we have reported the values of the survival function $S(t)$ of funds rated 5 stars.

\footnotetext{
${ }^{15}$ We notice that it corresponds to the sixth state $\mathcal{R}_{6}$ of the Markov chain.

${ }^{16}$ Let $\Lambda$ be the generator of the transition matrix $\pi$. We have:

$$
S(t)=\mathbf{e}_{6}^{\top} \exp (t \Lambda) \mathbf{e}_{6}
$$
}

The associate density function is:

$$
\begin{aligned}
f(t) & =-\partial S(t) \\
& =-\mathbf{e}_{6}^{\top} \Lambda \exp (t \Lambda) \mathbf{e}_{6}
\end{aligned}
$$


MUTUAL FUND RATINGS \& PERFORMANCE PERSISTENCE

Table 4: Survival probability of equity funds rated 5 stars

\begin{tabular}{c|cccccccc} 
Maturity & $0 \mathrm{M}$ & $1 \mathrm{M}$ & $3 \mathrm{M}$ & $6 \mathrm{M}$ & $9 \mathrm{M}$ & $1 \mathrm{Y}$ & $2 \mathrm{Y}$ & $3 \mathrm{Y}$ \\
\hline Europe & 100.0 & 83.9 & 61.2 & 41.3 & 30.2 & 23.5 & 12.8 & 10.0 \\
US & 100.0 & 84.2 & 61.5 & 41.1 & 29.4 & 22.3 & 11.5 & 8.9 \\
EM & 100.0 & 85.0 & 63.2 & 43.3 & 31.6 & 24.4 & 12.8 & 9.8
\end{tabular}

Table 5: Estimated one-month transition matrix for bond Euro diversified

\begin{tabular}{c|cccccc}
\hline & $\mathrm{NR}$ & $\star$ & $\star \star$ & $\star \star \star$ & $\star \star \star \star$ & $\star \star \star \star \star$ \\
\hline $\mathrm{NR}$ & 97.65 & 0.16 & 0.57 & 0.88 & 0.50 & 0.25 \\
$\star$ & 0.49 & 87.44 & 10.84 & 0.98 & 0.20 & 0.04 \\
$\star \star$ & 0.23 & 4.15 & 84.84 & 10.38 & 0.27 & 0.12 \\
$\star \star \star$ & 0.27 & 0.14 & 5.60 & 87.51 & 6.35 & 0.13 \\
$\star \star \star \star$ & 0.15 & 0.02 & 0.22 & 10.09 & 84.47 & 5.06 \\
$\star \star \star \star \star$ & 0.16 & 0.03 & 0.06 & 0.77 & 14.32 & 84.65
\end{tabular}

Table 6: Survival probability of bond funds rated 5 stars

\begin{tabular}{c|cccccccc} 
Maturity & $0 \mathrm{M}$ & $1 \mathrm{M}$ & $3 \mathrm{M}$ & $6 \mathrm{M}$ & $9 \mathrm{M}$ & $1 \mathrm{Y}$ & $2 \mathrm{Y}$ & $3 \mathrm{Y}$ \\
\hline Europe & 100.0 & 84.7 & 62.5 & 42.5 & 31.1 & 24.2 & 13.1 & 10.0 \\
US & 100.0 & 82.1 & 57.3 & 36.1 & 24.8 & 18.4 & 9.6 & 7.8 \\
EM & 100.0 & 80.1 & 53.8 & 32.8 & 22.3 & 16.6 & 9.1 & 7.7
\end{tabular}

\subsection{Measuring the persistence of ratings}

One way to measure the persistence of ratings is to consider the discrepancy between the probability to stay at the initial state and the probability to go in another state:

$$
d_{k}(t)=\operatorname{Pr}\left\{R(t)=\mathcal{R}_{k} \mid R(0)=\mathcal{R}_{k}\right\}-\operatorname{Pr}\left\{R(t) \neq \mathcal{R}_{k} \mid R(0)=\mathcal{R}_{k}\right\}
$$

By construction, the function $d_{k}(t)$ is a decreasing function of $t$ (Figure 1) and takes its value in the range $[-1,1]$. It is equal to 1 if $t=0$ and it is equal to $2 \operatorname{Pr}\left\{R(t)=\mathcal{R}_{k}\right\}-1$ when $t$ tends to infinity ${ }^{17}$.

We then define the persistence time as the maturity such that the the probabilities to stay in the state or outside the state are equal. More formally, we have:

$$
\tau_{k}=\inf \left\{t>0: d_{k}(t) \leq 0\right\}
$$

The results are reported in Figure 2. We remark that these persistence times are very low, less than one year for all ratings. For example, the persistence time of five-star rated funds is respectively 4.2 and 4.7 months for Europe equity blend and bond Euro diversified categories. It is also interesting to notice that the persistence time of lower ratings (one or two stars) is not longer than higher ratings. We do not retrieve the results of some authors, which find that persistence is higher for losers than winners.

\subsection{Comparison with credit ratings}

If we compare persistence times of fund rating systems with persistence times of credit rating systems (see results in Figure 3), we notice that they are not of same order. For AAA

\footnotetext{
${ }^{17}$ This level is represented by the dashed line in Figure 1 and depends on the proportion of funds in the rating class.
} 
Figure 1: Persistence measure $d_{k}(t)$ for Europe blend equity
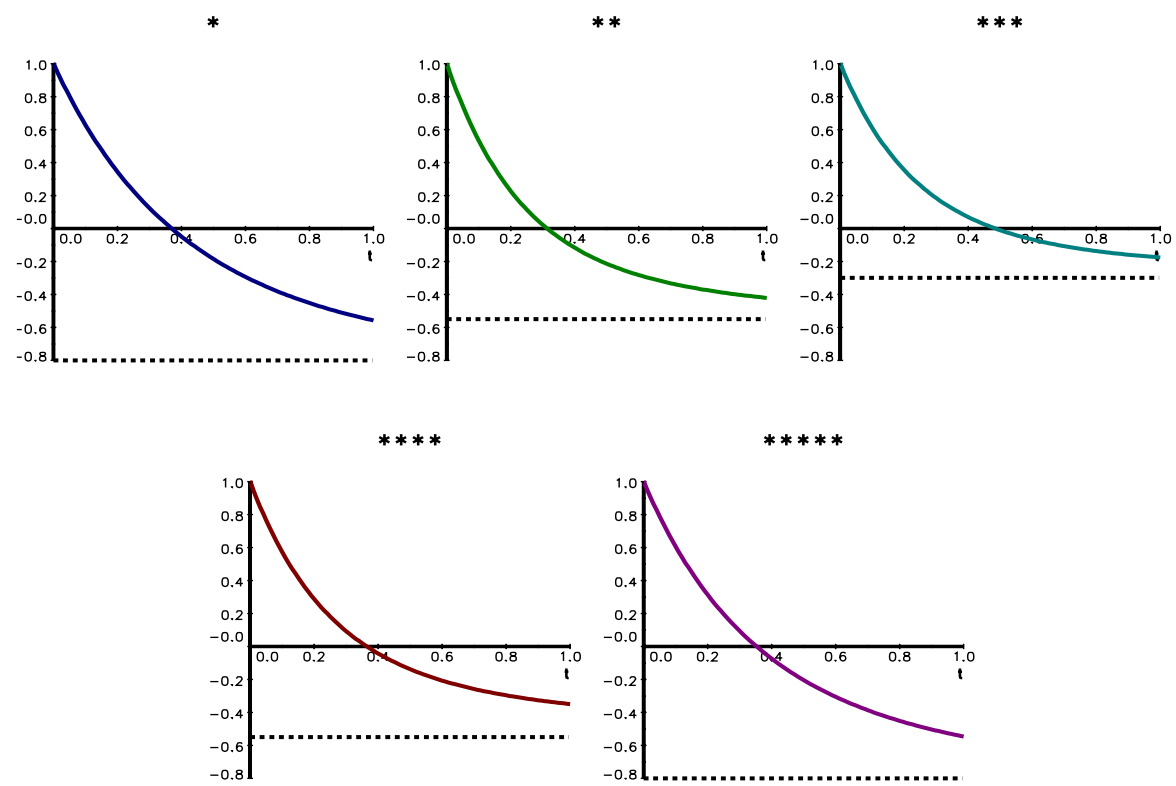

Figure 2: Persistence times $\tau_{k}$ for equity and bond funds
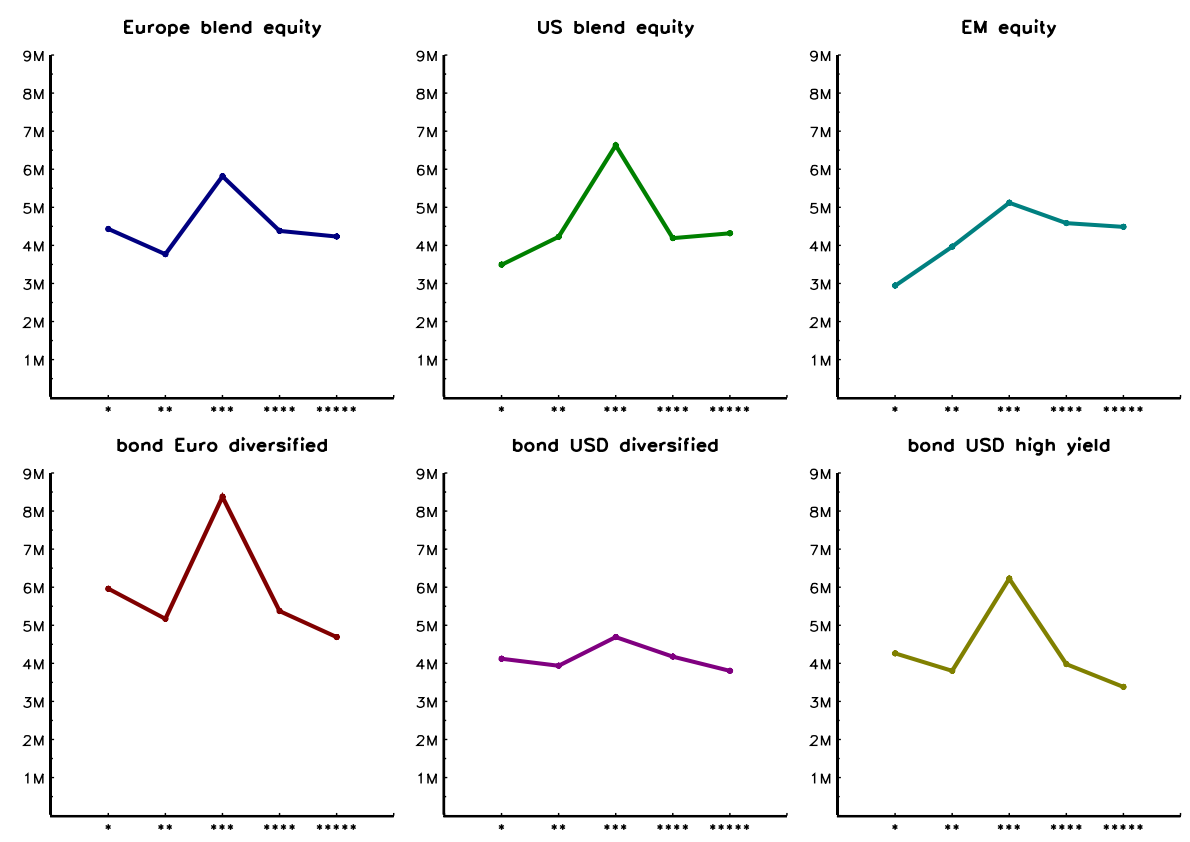
ratings, it is about 10 years. It is certainly the main difference between fund rating systems and credit rating systems. Fortunately, the latter exhibit more persistence of ratings.

Figure 3: Persistence times $\tau_{k}$ of the $\mathrm{S} \& \mathrm{P}$ credit ratings system

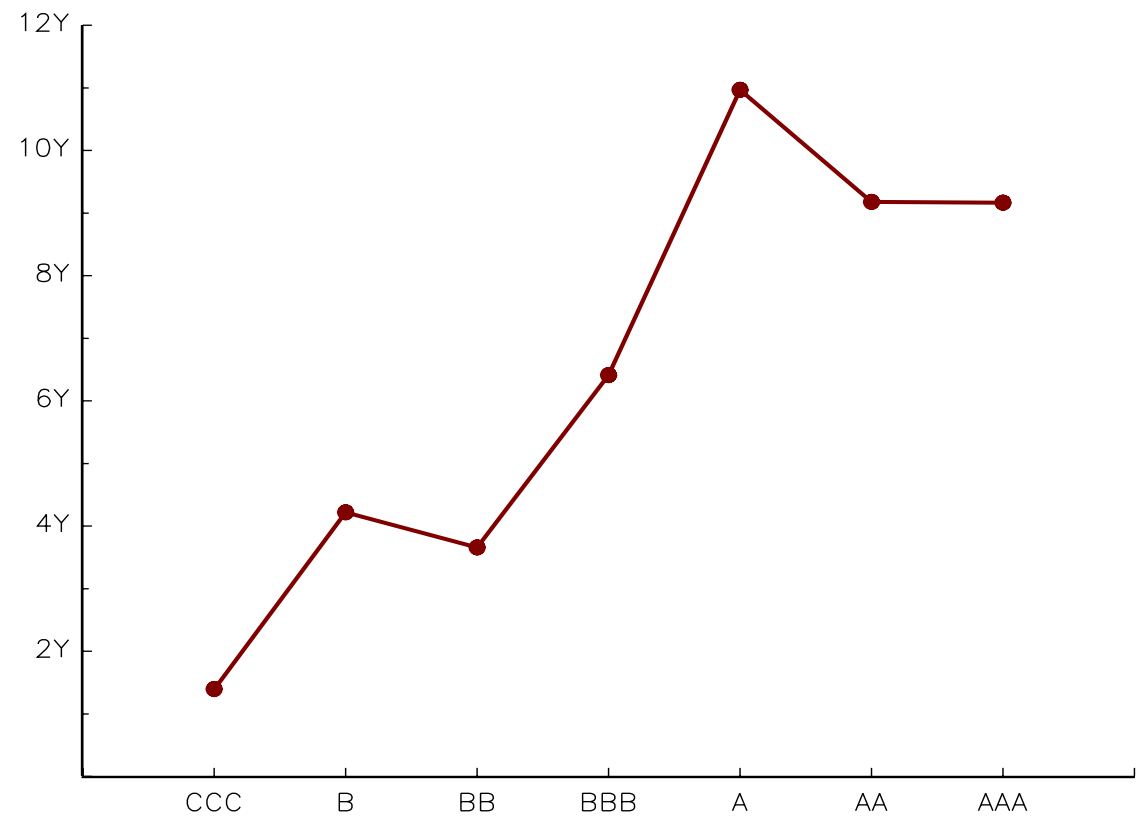

\section{On the importance of style}

One of the big issue of active management is the style of the fund manager. Let us consider the case of an equity fund. The difference between the performance of the fund and the performance of the benchmark may not be perfectly explained by the stock picking process, because of the following reasons.

1. The investment universe of the fund may be different from the benchmark universe. Generally, it is larger. For example, some mutual funds whose benchmark is the S\&P 500 index may invest in a universe closer to the Russell 1000 or 2000 index.

2. The fund may have some sector biases. If a fund takes some big bets in few sectors, the difference of the performance will be mainly explained by the sector positioning and not necessarily by the stock picking process. For example, overweighting the banking sector was a good bet until 2008 and the financial crisis.

3. More generally, the performance of the fund may be largely explained by some style factors.

These style biases may be taken into account by rating systems ${ }^{18}$ (see Box 2).

\footnotetext{
${ }^{18}$ Asset categories in Morningstar are implicitly defined so that funds in one category present the same style.
} 


\section{Box 2: The Europerformance/Edhec rating methodology}

The ratings are constructed by combining three criteria. First, one measures extreme risks using a Corner-Fisher Value-at-Risk at a 99\% confidence level. If the VaR of the fund is too high, the fund is not rated. Second, the alpha of the fund is estimated. It is done in two steps. In a first step, the style analysis of Sharpe is considered to build the implied benchmark of the fund. When this benchmark is selected, one deduces alpha by a regression analysis:

$$
R_{i, t}-R_{f}=\alpha+\sum_{j=1}^{n} \beta_{j}\left(R_{j, t}-R_{f}\right)+\varepsilon_{t}
$$

The alpha criterion allows us to distinguish funds rated below and above 3 stars. For example, the 4 and 5 stars correspond to funds which have a strictly positive alpha. The distinction between 4 and 5 stars is done using a gain frequency measure. It corresponds to the number of times in percent that the fund has delivered performance that was better than that of its benchmark. If the gain frequency measure is less than $50 \%$, the fund is rated 4 stars, otherwise it is rated 5 stars. Finally, a super rating is attributed to funds rated 5 stars and which have a Hurst exponent $H$ larger than $1 / 2$.

\subsection{The Fama-French model}

Let $R_{i}$ be the return of the $i^{\text {th }}$ asset and $R_{f}$ be the risk-free rate. In the Capital Asset Pricing Model (CAPM) of Sharpe (1964) and Lintner (1965), we have:

$$
\mathbb{E}\left[R_{i}\right]=R_{f}+\beta_{i}\left(\mathbb{E}\left[R_{m}\right]-R_{f}\right)
$$

where $R_{m}$ is the return of the market portfolio and $\beta_{i}$ is the measure of the systematic risk defined by:

$$
\beta_{i}=\frac{\operatorname{cov}\left(R_{i}, R_{m}\right)}{\operatorname{var}\left(R_{m}\right)}
$$

This model is also called the one-factor pricing model, because the stock return is entirely explained by one risk factor represented by the market. According to Fama and French (2004), this model is the centerpiece of MBA investment courses and is widely used in finance by practitioners despite a large body of evidence in the academic literature of the invalidation of this model:

"The attraction of the CAPM is that it offers powerful and intuitively pleasing predictions about how to measure risk and the relation between expected return and risk. Unfortunately, the empirical record of the model is poor - poor enough to invalidate the way it is used in applications." (Fama and French, 2004, p. 25)

The CAPM is certainly the most used model to measure the performance of mutual funds. Jensen (1968) proposes to estimate the CAPM using the following time-series regression:

$$
R_{i, t}-R_{f, t}=\alpha_{i}+\beta_{i}\left(R_{m, t}-R_{f, t}\right)+u_{i, t}
$$

where the error term $u_{i, t}$ is serially independent and verifies $\mathbb{E}\left[u_{i, t}\right]=0$ and $\operatorname{var}\left(u_{i, t}\right)=\sigma_{i}^{2}$. He uses the estimate $\alpha_{i}$ (the famous Jensen alpha) to measure abnormal performance of mutual funds. In particular, Jensen considers that a significantly positive $\alpha_{i}$ indicates that the fund manager has an ability to forecast stock prices. Jensen alpha continues to be used today even if it is largely criticized by the academic literature: 
«[... because of the empirical failings of the CAPM, even passively managed stock portfolios produce abnormal returns if their investment strategies involve tilts toward CAPM problems (Elton, Gruber, Das and Hlavka, 1993). For example, funds that concentrate on low beta stocks, small stocks or value stocks will tend to produce positive abnormal returns relative to the predictions of the Sharpe-Lintner CAPM, even when the fund managers have no special talent for picking winners.»(Fama and French, 2004, p. 25)

In 1992, Fama and French studied several factors to explain average returns (size, E/P, leverage and book-to-market equity). Fama and French (1993) extend their empirical work and propose a three factor-model:

$$
\mathbb{E}\left[R_{i}\right]-R_{f}=\beta_{i}^{m}\left(\mathbb{E}\left[R_{m}\right]-R_{f}\right)+\beta_{i}^{s m b} \mathbb{E}\left[R_{s m b}\right]+\beta_{i}^{h m l} \mathbb{E}\left[R_{h m l}\right]
$$

where $R_{s m b}$ is the return of small stocks minus the return of large stocks and $R_{h m l}$ is the return of stocks with high book-to-market values minus the return of stocks with low bookto-market values. This model is supported by a large body of empirical literature and is today the standard model in the asset management industry. However, to estimate the style of a fund, the style analysis of Sharpe is preferred.

\subsection{The style-based analysis}

The style-based analysis was introduced by Sharpe (1992) to provide a better understanding of mutual fund performance. Indeed, the comparison with the fund benchmark can often be misleading if the manager develops investment biases in favor of certain sectors or geographical areas. To assess the fund's genuine performance, it is important to identify its effective exposures and the components of its returns. The style-based analysis is one solution to address this problem.

First of all, the style factors or market exposures have to be selected. To do so, a qualitative study of the manager's effective investment universe is necessary. The selected factors should cover the entire universe, be mutually exclusive and present low correlations. To illustrate these factors, here is a list of popular indices/portfolios used when dealing with equity mutual funds:

- Style indices

They are used to distinguish if the manager follows a growth or value investment philosophy.

- Capitalization indices

They can be large, mid or small and provide information on the size of the companies held in the fund.

- Sectors indices

They allow us to know if the fund implements particular bets on specific industries.

- Geographical indices

They are used to split the fund exposures by country or regions. 
The return $R_{i, t}$ of the fund $i$ at date $t$ can be explained by the returns $R_{j, t}$ of the style factor according to the following equation:

$$
\begin{aligned}
R_{i, t} & =\sum_{j=1}^{n} w_{i, j} R_{j, t}+u_{i, t} \\
& \text { u.c. } \quad w_{i, j} \geq 0 \text { and } \sum_{j=1}^{n} w_{i, j}=1
\end{aligned}
$$

The coefficients $w_{i, j}$ are the weights attributed to the $j^{\text {th }}$ style factor. They must be positive and sum to one in order to reflect the constraints faced by the manager (no short selling, $100 \%$ fully invested). The residual terms $\varepsilon_{i, t}$ are assumed to be uncorrelated among each other and across time. Looking at the above formula, the fund performance can be broken down into two distinct components:

- The component $\sum_{j=1}^{n} w_{i, j} R_{j, t}$.

This first term captures the part of the fund returns explained by the style factors. It can be seen as the performance of the asset allocation. Furthermore, the style weights are useful to know if the manager is consistent with his stated investment strategy. As it is widely agreed that performance is mainly driven by the asset allocation, this information is valuable for the investor.

- The component $u_{i, t}$.

This second term is the residual performance explained by the active management of the fund. It means that $\mathbb{E}\left[u_{i, t}\right]$ is not necessarily equal to 0 . It can be further decomposed into the manager's skill in performing the stock-picking, the tactical asset allocation and the performance linked to factors absent from the model.

By looking at the $R^{2}$ of the regression, it is therefore possible to get an indication of the percentage returns explained by the asset allocation and by the active management. For instance, a high $R^{2}$ will imply a passive management. On the contrary, a low $R^{2}$ will not necessarily indicate an active management as it can be a consequence of a model misspecification.

Let us consider the example of two US equity mutual funds. The first one is Franklin US Opportunities managed according to a growth investment strategy since its inception in March 2000. We apply a style-based analysis using the MSCI indices for the four reference styles large cap / smid Cap and growth / value as well as the cross sub-indices. The style-based analysis is performed with weekly returns and a rolling-period of 52 weeks. We consider 5 sets of factors:

(a) large / smid

(b) value / growth

(c) large value / large growth

(d) smid value / smid growth

(e) large value / large growth / smid value / smid growth

Results for year 2009 are presented in Table 7. Considering only large cap indices model (c) - leads us to an implicit allocation of $17 \%$ on the value factor and $83 \%$ on the growth factor. Introducing smid-cap factors in the regression improves the explanatory power of the model as showed by the increase in the $R^{2}$ measure. It also reveals that part 
of the variation in returns previously explained by the value factor might be in fact due to smid-cap factors. According to model (e), we now obtain an allocation of $100 \%$ in growth factors. These results are in accordance with the fund's self-reported investment strategy. This example shows the importance of appropriately selecting factors consistent with the manager's investment universe. Finally, the $R^{2}$ coefficient of $97.6 \%$ implies that a great part of the performance may be explained by asset allocation rather than stock picking. Looking at the rolling regression results in Figure 4 leads us to the same conclusion regarding the importance of the smid-cap factors. In addition, it provides insight about the evolution of the style exposure over time. It is however important to keep in mind that weights represent one-year average exposures rather than an instantaneous picture of the fund allocation. We observe a consistence in the growth management style as well as a progressive shift towards the large cap factor in recent years.

Table 7: Style analysis of Franklin US Opportunities for the year 2009

\begin{tabular}{c|cccccccc|c} 
& $w_{L}$ & $w_{S}$ & $w_{V}$ & $w_{G}$ & $w_{L V}$ & $w_{L G}$ & $w_{S V}$ & $w_{S G}$ & $R^{2}$ \\
\hline (a) & 62.7 & 37.3 & & & & & & & 93.0 \\
(b) & & & 12.1 & 87.9 & & & & & 95.5 \\
(c) & & & & & 16.9 & 83.1 & & & 93.9 \\
(d) & & & & & & & 0.0 & 100.0 & 95.4 \\
(e) & & & & & 0.0 & 41.7 & 0.0 & 58.3 & 97.6
\end{tabular}

Figure 4: Style analysis of Franklin US Opportunities
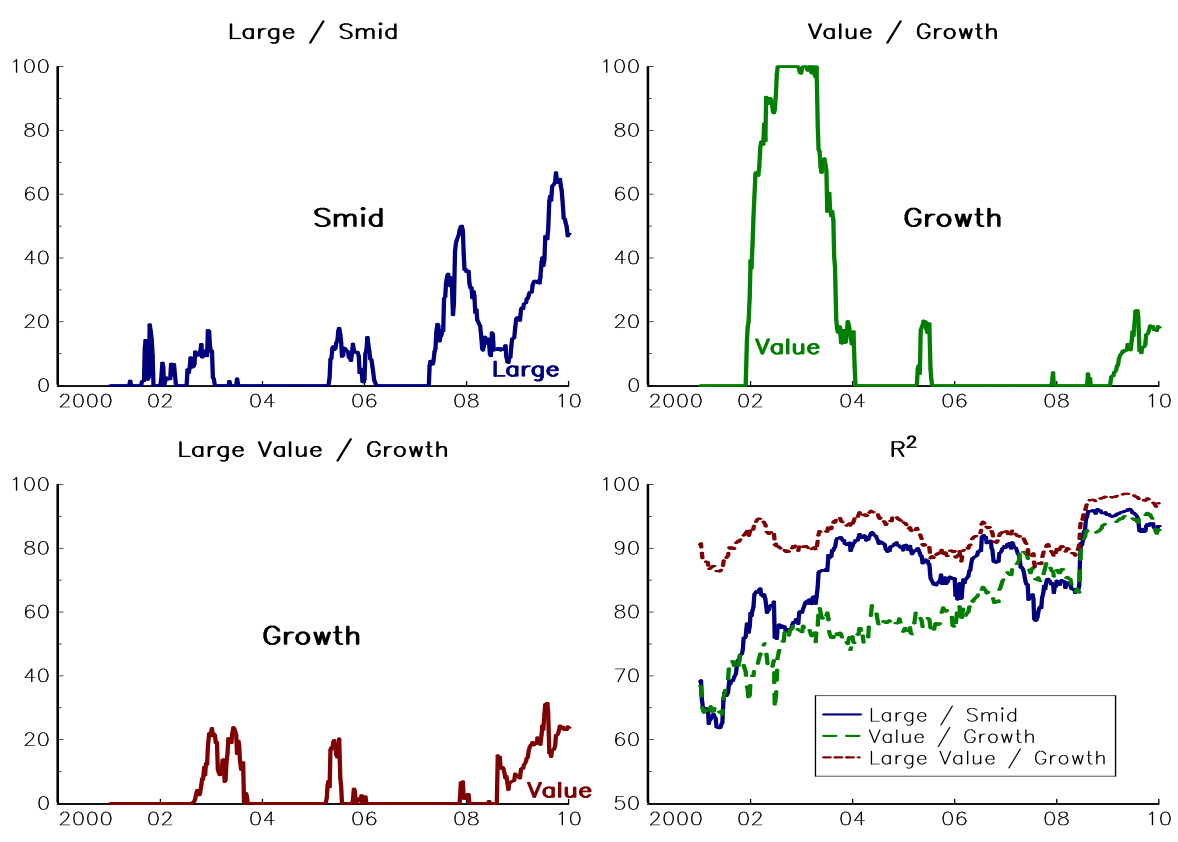

We now proceed to the same analysis with Nordea North American Value. This fund follows a value strategy since it was launched in March 1997. In this case, the regression fails to properly identify the style exposures as indicated by the low $R^{2}$ coefficient. Figure 5 indicates large variations in the factors exposures and little relevance with regard to the 
self-reported fund strategy. However, a study of the fund holdings indicates clearly that the fund follows a value strategy. It also reveals that the fund displays significant sector biases which could not be captured by the set of model factors.

Table 8: Style analysis of Nordea North American Value for the year 2009

\begin{tabular}{c|cccccccc|c} 
Model & $w_{L}$ & $w_{S}$ & $w_{V}$ & $w_{G}$ & $w_{L V}$ & $w_{L G}$ & $w_{S V}$ & $w_{S G}$ & $R^{2}$ \\
\hline (a) & 22.8 & 77.2 & & & & & & & 73.1 \\
(b) & & & 88.2 & 11.8 & & & & & 72.1 \\
(c) & & & & & 88.2 & 11.8 & & & 71.5 \\
(d) & & & & & & & 53.0 & 47.0 & 72.8 \\
(e) & & & & & 40.3 & 0.0 & 29.5 & 30.2 & 74.0
\end{tabular}

Figure 5: Style analysis of Nordea North American Value
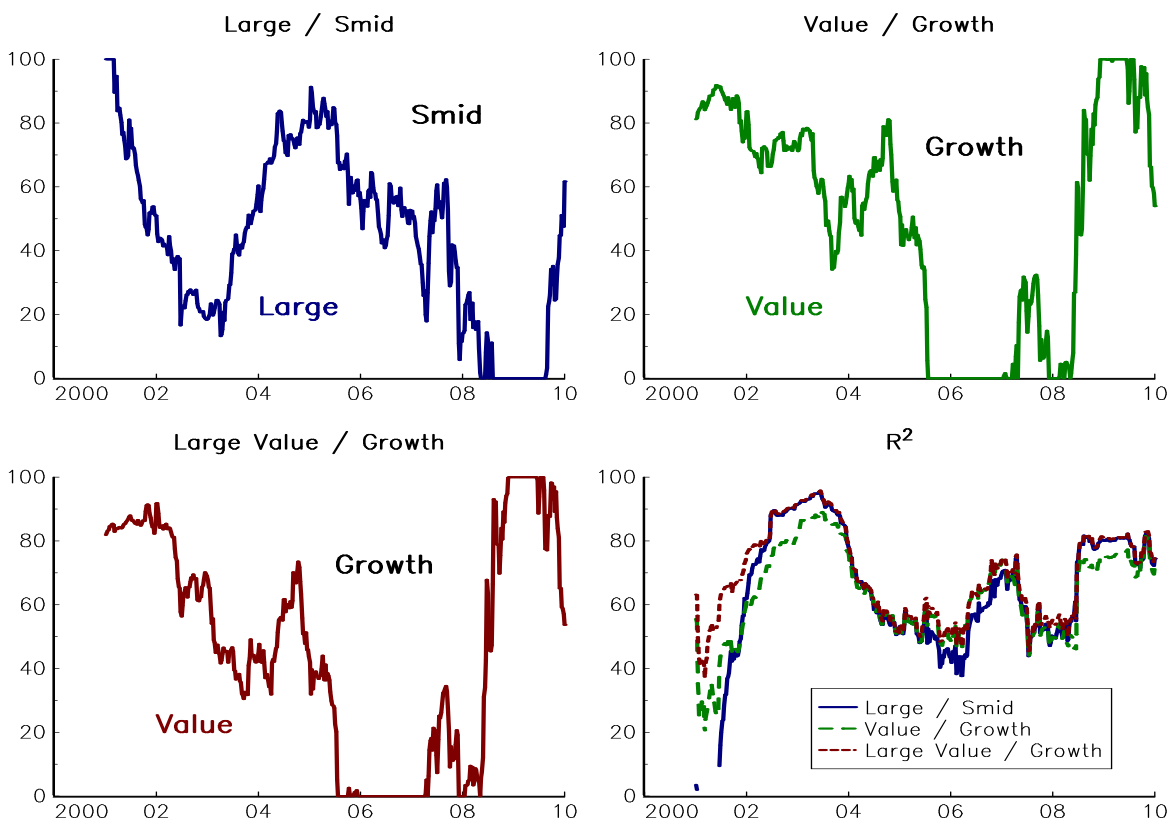

These two examples show that it is difficult to analyze quantitatively the style of mutual equity funds without an in-depth qualitative analysis. The first example shows that results depend on the set of factors. In the second example, the style-based analysis does not succeed in identifying the fund's style. That is why a systematic procedure to measure the style will certainly not produce anything satisfactory.

\subsection{Style and fund rating systems}

To illustrate the importance of style on the performance, we focus on two previous categories: Europe blend equity funds and Euro diversified bond funds ${ }^{19}$. We consider the funds which have a Morningstar rating in March 2009. We then compute the one-year return of these funds between March 2009 and March 2010, and rank them in quantiles similar to the

\footnotetext{
${ }^{19}$ We recall that the funds in this category are invested in both government and corporate bonds.
} 
Morningstar system ${ }^{20}$. We have reported the results in Tables 9 and 10. They may be viewed as the probability transition matrix between the March 2009 rating and the next one-year performance. In these two examples, we observe that a large proportion of the funds which were rated five stars are in the lower quantile $Q_{1}$. Inversely, a high proportion of one-star funds are in the higher quantile $Q_{5}$. How can we explain these results? In March 2009, the performance of many well-rated funds was due to their defensive style (low beta to the market for equity funds and exposure to govies rather than corporate bonds for diversified bond funds). When the market rebounded, most of them did not adjust their style and underperformed their peer groups.

Table 9: Results for Europe blend equity funds

\begin{tabular}{c|ccccc} 
& $Q_{1}$ & $Q_{2}$ & $Q_{3}$ & $Q_{4}$ & $Q_{5}$ \\
\hline$\star$ & 20.00 & 6.67 & 20.00 & 16.67 & 36.67 \\
$\star \star$ & 4.21 & 15.79 & 35.79 & 35.79 & 8.42 \\
$\star \star \star$ & 6.90 & 24.71 & 36.78 & 22.41 & 9.20 \\
$\star \star \star \star$ & 3.54 & 22.12 & 45.13 & 21.24 & 7.96 \\
$\star \star \star \star \star$ & 32.14 & 37.50 & 16.07 & 7.14 & 7.14
\end{tabular}

Table 10: Results for Euro diversified bond funds

\begin{tabular}{c|ccccc} 
& $Q_{1}$ & $Q_{2}$ & $Q_{3}$ & $Q_{4}$ & $Q_{5}$ \\
\hline$\star$ & 4.17 & 6.25 & 2.08 & 20.83 & 66.67 \\
$\star \star$ & 12.40 & 10.74 & 22.31 & 39.67 & 14.88 \\
$\star \star \star$ & 10.92 & 20.69 & 40.80 & 27.01 & 0.57 \\
$\star \star \star \star$ & 8.20 & 36.89 & 45.08 & 8.20 & 1.64 \\
$\star \star \star \star \star$ & 6.45 & 35.48 & 50.00 & 8.06 & 0.00
\end{tabular}

\section{Conclusion}

We review the academic research on mutual fund performance, in particular its persistence. As this concept is closely related to the measurement of performance and the characterization of what constitutes outperformance, different approaches were explored leading to various conclusions. From the early studies based on risk-adjusted performance with a single risk factor, we moved to more comprehensive methods adjusting returns from a set of systematic risk factors and adjusting exposures with time-varying coefficients. These first studies conclude generally on the evidence of performance persistence. However, this evidence is not confirmed by recent studies using these alternative approaches. Furthermore, when evidence of persistence is exhibited, it tends to be more significant for poorly performing funds than for funds with outstanding past returns and it is only observed on short-term horizons.

In this paper, an alternative approach is considered to address the issue of persistence. Using a Markov chain framework, we model the evolution of the Morningstar ratings over time. These ratings which are based on risk-adjusted returns can be used to assess the relative performance of a fund among its peers. Once again, our results support that persistence exists on short-term horizons but becomes less relevant over longer periods. For funds

\footnotetext{
${ }^{20} Q_{1}$ represents the last $10 \%, Q_{2}$ represents the next $22.5 \%$, etc. The best performers correpond to the $Q_{5}$ quantile (top 10\%).
} 
rated five stars, the time of persistence is equal to five months on average. If we consider credit rating systems, we find that the persistence of a AAA rating is about 10 years. The robustness of fund and credit rating systems cannot be compared.

We find that it is difficult to compare the performance of mutual funds because they are not homogeneous in terms of investment behavior. A study of style through the FamaFrench model or the Sharpe style-based analysis is a good starting point to get insight about mutual fund exposures and sources of return and risk. However, due to the variety of possible investment biases and management strategies, only a qualitative analysis can unveil all the aspects of a fund's performance and risks.

We conclude that selection of mutual funds cannot be done using exclusively quantitative analysis. Qualitative analysis is a necessity when investing in mutual funds and justifies the role of analysts in the mutual funds industry. Efforts should be directed to the understanding and selection of appropriate mutual funds with respects to the investor objectives rather than as a desperate quest for high recurrent alphas. Rather than focusing on top ranked funds within each peer-group, close attention should be paid to style drifts and other hidden determinants of funds behavior not indicated in the self-reported manager style. In this context, active management of active management is no longer an option but a necessity when investing in mutual funds. 


\section{Appendix}

\section{A Results for other asset categories}

Table 11: Estimated one-month transition matrix for US blend equity

\begin{tabular}{c|cccccc}
\hline & $\mathrm{NR}$ & $\star$ & $\star \star$ & $\star \star \star$ & $\star \star \star \star$ & $\star \star \star \star \star$ \\
\hline $\mathrm{NR}$ & 97.80 & 0.15 & 0.50 & 0.73 & 0.58 & 0.23 \\
$\star$ & 0.07 & 81.25 & 17.83 & 0.63 & 0.07 & 0.14 \\
$\star \star$ & 0.23 & 5.12 & 81.92 & 12.59 & 0.14 & 0.00 \\
$\star \star \star$ & 0.23 & 0.04 & 6.48 & 84.66 & 8.50 & 0.09 \\
$\star \star \star \star$ & 0.19 & 0.02 & 0.32 & 13.33 & 81.20 & 4.94 \\
$\star \star \star \star \star$ & 0.23 & 0.00 & 0.05 & 0.61 & 14.93 & 84.18
\end{tabular}

Table 12: Estimated one-month transition matrix for EM equity

\begin{tabular}{c|cccccc}
\hline & $\mathrm{NR}$ & $\star$ & $\star \star$ & $\star \star \star$ & $\star \star \star \star$ & $\star \star \star \star \star$ \\
\hline $\mathrm{NR}$ & 97.92 & 0.14 & 0.49 & 0.67 & 0.52 & 0.27 \\
$\star$ & 0.53 & 78.20 & 20.21 & 0.74 & 0.11 & 0.21 \\
$\star \star$ & 0.09 & 5.79 & 80.28 & 13.67 & 0.12 & 0.06 \\
$\star \star \star$ & 0.19 & 0.08 & 8.82 & 82.60 & 8.26 & 0.06 \\
$\star \star \star \star$ & 0.11 & 0.00 & 0.17 & 11.98 & 82.81 & 4.93 \\
$\star \star \star \star \star$ & 0.24 & 0.08 & 0.08 & 0.16 & 14.45 & 85.00
\end{tabular}

Table 13: Estimated one-month transition matrix for bond USD diversified

\begin{tabular}{c|cccccc}
\hline & $\mathrm{NR}$ & $\star$ & $\star \star$ & $\star \star \star$ & $\star \star \star \star$ & $\star \star \star \star \star$ \\
\hline $\mathrm{NR}$ & 97.88 & 0.24 & 0.29 & 0.71 & 0.60 & 0.29 \\
$\star$ & 0.83 & 82.53 & 14.81 & 1.16 & 0.50 & 0.17 \\
$\star \star$ & 0.06 & 5.56 & 80.48 & 13.19 & 0.65 & 0.06 \\
$\star \star \star$ & 0.07 & 0.04 & 8.50 & 81.38 & 9.80 & 0.22 \\
$\star \star \star \star$ & 0.15 & 0.10 & 0.64 & 13.59 & 80.73 & 4.81 \\
$\star \star \star \star \star$ & 0.61 & 0.00 & 0.30 & 0.91 & 16.06 & 82.12
\end{tabular}

Table 14: Estimated one-month transition matrix for bond USD high yield

\begin{tabular}{c|cccccc}
\hline & $\mathrm{NR}$ & $\star$ & $\star \star$ & $\star \star \star$ & $\star \star \star \star$ & $\star \star \star \star \star$ \\
\hline $\mathrm{NR}$ & 97.96 & 0.12 & 0.45 & 0.51 & 0.69 & 0.27 \\
$\star$ & 0.45 & 83.78 & 11.71 & 2.70 & 1.35 & 0.00 \\
$\star \star$ & 0.45 & 3.87 & 80.36 & 14.14 & 0.89 & 0.30 \\
$\star \star \star$ & 0.16 & 0.57 & 7.46 & 83.71 & 7.62 & 0.49 \\
$\star \star \star \star$ & 0.25 & 0.37 & 1.00 & 12.81 & 80.35 & 5.22 \\
$\star \star \star \star \star$ & 0.00 & 0.37 & 0.00 & 1.50 & 17.98 & 80.15
\end{tabular}




\section{B The mathematical and statistical framework of Markov chains}

\section{B.1 Modeling a Markov chain in continuous time}

We consider a rating system defined by a set of $K$ states $\mathcal{R}=\left\{\mathcal{R}_{1}, \mathcal{R}_{2}, \ldots, \mathcal{R}_{K}\right\}$. Consider a mutual fund $n$ with rating $\mathcal{R}_{k}$ at time $t$. We note $R_{(n)}(t)=\mathcal{R}_{k}$ where $R_{(n)}(t)$ is the random variable which represents the rating of the mutual fund $n$ at time $t$. Let us define $\pi_{(n)}\left(s, k_{1} ; t, k_{2}\right)$ as the probability that the rating of the mutual fund goes from $\mathcal{R}_{k_{1}}$ at time $s$ to $\mathcal{R}_{k_{2}}$ at time $t$. We have:

$$
\pi_{(n)}\left(s, k_{1} ; t, k_{2}\right)=\operatorname{Pr}\left\{R_{(n)}(t)=\mathcal{R}_{k_{2}} \mid R_{(n)}(s)=\mathcal{R}_{k_{1}}\right\}
$$

This dynamic system is often modeled using a homogeneous Markov chain. Let $\pi=\left(\pi_{i, j}\right)$ be the transition matrix between two consecutive observation periods. This matrix has the properties $\pi_{i, j} \geq 0$ and $\sum_{j=1}^{K} \pi_{i, j}=1$. In this case, we have:

$$
\pi_{(n)}\left(s, k_{1} ; t, k_{2}\right)=\mathbf{e}_{k_{1}}^{\top} \pi^{(t-s)} \mathbf{e}_{k_{2}}
$$

Let us now consider the continuous time $t \in \mathbb{R}_{+}$. We note $\pi(s ; t)$ the transition matrix from time $s$ to time $t$. The transition matrix at period $t$ corresponds to $\pi(t)=\pi(0 ; t)$. The generator of the transition matrix $\pi(t)$ is the matrix $\Lambda=\left(\lambda_{i, j}\right)$ defined by:

$$
\pi(t)=\exp (t \Lambda)
$$

The interpretation of this matrix is the following. If the transition probability from the state $i$ to the state $j(j \neq i)$ in a short elapsed time $\Delta t$ is approximately proportional to $\Delta t$, we have $\pi(t, i ; t+\Delta t, j)=\lambda_{i, j} \Delta t$. The matrix form is $\pi(t ; t+\Delta t)=\Lambda \Delta t$. It comes that $\pi(t+\Delta t)=\pi(t) \pi(t ; t+\Delta t)=\pi(t) \Lambda \Delta t$ and we have $\mathrm{d} \pi(t)=\pi(t) \Lambda \mathrm{d} t$. Because $\exp (\mathbf{0})$ is equal to the identity matrix, we obtain the solution $\pi(t)=\exp (t \Lambda)$. We may interpret $\lambda_{i, j} \geq 0(j \neq i)$ as the instantaneous transition rate. Moreover, we may show that $\Lambda$ is a Markov generator if it verifies $\sum_{j=1}^{K} \lambda_{i, j}=0$. In the discrete case, we have:

$$
\pi_{(n)}\left(s, k_{1} ; t, k_{2}\right)=\mathbf{e}_{k_{1}}^{\top} e^{\Lambda(t-s)} \mathbf{e}_{k_{2}}
$$

\section{B.2 Maximum likelihood estimation for Markov chains}

We consider an homogeneous Markov chain with $\pi$ the unknown transition matrix. We would like to estimate the $K^{2}$ parameters $\left(\pi_{i, j}\right)$ defined by:

$$
\pi_{i, j}=\operatorname{Pr}\left\{R_{(n)}(t+1)=\mathcal{R}_{j} \mid R_{(n)}(t)=\mathcal{R}_{i}\right\}
$$

We observe the ratings of $N$ mutual funds for the dates $t=0,1, \ldots, T$. We denote $r_{(n)}(t)$ the realization of the random variable $R_{(n)}(t)$. Using the Markov property, it comes that the likelihood for the $n^{\text {th }}$ mutual fund is given by:

$$
L_{n}=\operatorname{Pr}\left\{R_{(n)}(0)=r_{(n)}(0)\right\} \prod_{t=1}^{T} \pi_{r_{(n)}(t-1), r_{(n)}(t)}
$$

Let $S_{i, j}^{(n)}$ be the number of times that the rating $\mathcal{R}_{i}$ is followed by the rating $\mathcal{R}_{j}$. The log-likelihood is:

$$
\ell=\sum_{n=1}^{N} \operatorname{Pr}\left\{R_{(n)}(0)=r_{(n)}(0)\right\}+\sum_{n=1}^{N} \sum_{i=1}^{K} \sum_{j=1}^{K} \pi_{i, j}^{S_{i, j}^{(n)}}
$$


The ML estimator is then the solution of the following maximization program:

$$
\begin{array}{r}
\left(\hat{\pi}_{i, j}\right)=\arg \max \sum_{n=1}^{N} \sum_{i=1}^{K} \sum_{j=1}^{K} \pi_{i, j}^{S_{i, j}^{(n)}} \\
\text { u.c. } \quad \pi_{i, j} \geq 0 \text { and } \sum_{j=1}^{K} \pi_{i, j}=1
\end{array}
$$

We use the SQP algorithm to estimate $\left(\hat{\pi}_{i, j}\right)$.

\section{B.3 Schur decomposition and matrix functions}

Let $A$ be a square matrix. The Schur decomposition is:

$$
A=T S T^{*}
$$

with $T$ a unitary matrix ( $T$ is called the transformation matrix) and $S$ a upper diagonal matrix ( $S$ is called the real Schur form).

Let $f$ be a real function defined by:

$$
\begin{aligned}
f: & \mathbb{R} \longrightarrow \mathbb{R} \\
& x \longmapsto y=f(x)
\end{aligned}
$$

It is possible to define this function in the space $\mathbb{M}$ of square matrices:

$$
\begin{aligned}
f: \mathbb{M} & \longrightarrow \mathbb{M} \\
& A \longmapsto B=f(A)
\end{aligned}
$$

Let us consider the case of the square root real function $f(x)=\sqrt{x}=x^{1 / 2}$. If the square matrix $A$ is positive, we may define the matrix $B$ such that:

$$
B B^{*}=B^{*} B=A
$$

$B$ is called the square root of $A$ and we note $B=A^{1 / 2}$.

Let $f$ be a real function. There are several ways to generalize this function in the space of matrices. The most used generalization is based on the Taylor expansion:

$$
f(x)=f(0)+x f^{\prime}(0)+\frac{x^{2}}{2 !} f^{\prime \prime}(0)+\ldots
$$

We may show that if the series converge for $|x|<\alpha$, then the matrix function $f(A)$ defined by:

$$
f(A)=f(0)+A f^{\prime}(0)+\frac{A^{2}}{2 !} f^{\prime \prime}(0)+\ldots
$$

converge to a matrix $B$ if $|A|<\alpha$ and $A$ is a square matrix. We note $B=f(A)$. Let us consider the case of the exponential function. We have:

$$
f(x)=e^{x}=\sum_{k=0}^{\infty} \frac{x^{k}}{k !}
$$

We deduce that the matrix exponential is given by the following expression:

$$
B=e^{A}=\sum_{k=0}^{\infty} \frac{A^{k}}{k !}
$$


Note that the matrix logarithm of $B$ is then the matrix $A$ and we note $A=\ln B$.

Matrix functions are generally computed using the Schur decomposition. In most cases, we may compute $f(A)$ with:

$$
f(A)=T f(S) T^{*}
$$

where $A=T S T^{*}$ is the complex Schur decomposition of $A$. In the general case, we consider the algorithm 11.1.1 of Golub and Van Loan (1989) whereas in the case of the exponential function, we use their algorithm 11.3.1.

\section{B.4 Finding a valid Markov generator}

Let $\hat{\pi}(t)$ be a transition matrix between 0 and $t$. If $\hat{\pi}(t)$ is a Markov matrix, then there exists a generator $\Lambda$ such that:

$$
\hat{\pi}(t)=\exp (t \Lambda)
$$

An estimate of $\Lambda$ is also $\hat{\Lambda}$ defined by:

$$
\hat{\Lambda}=\frac{1}{t} \ln \hat{\pi}(t)
$$

$\hat{\Lambda}$ is a Markov generator if each off-diagonal element is positive and all its row-sums are 0 . If some off-diagonal elements are negative, it means that $\hat{\Lambda}$ is not a Markov generator and $\hat{\pi}(t)$ is not a Markov transition matrix. In order to obtain a valid generator, Israel et al. (2001) suggest two methods by replacing the negative off-diagonal entries with 0 and adding the appropriate value back into other entries to preserve the property of having row-sums 0 .

1. In the first method [IRW-1], we add the negative values back into the corresponding diagonal entry:

$$
\left\{\begin{array}{l}
\bar{\lambda}_{i, j}=\max \left(\hat{\lambda}_{i, j}, 0\right) \quad i \neq j \\
\bar{\lambda}_{i, i}=\hat{\lambda}_{i, i}+\sum_{j \neq i} \min \left(\hat{\lambda}_{i, j}, 0\right)
\end{array}\right.
$$

2. In the second method [IRW-2], we add the negative values back into all the entries of the same row which have the correct sign:

$$
\left\{\begin{array}{l}
G_{i}=\left|\hat{\lambda}_{i, i}\right|+\sum_{j \neq i} \max \left(\hat{\lambda}_{i, j}, 0\right) \\
B_{i}=\sum_{j \neq i} \max \left(-\hat{\lambda}_{i, j}, 0\right) \\
\bar{\lambda}_{i, j}=\left\{\begin{array}{l}
0 \quad i \neq j \text { and } \hat{\lambda}_{i, j}<0 \\
\hat{\lambda}_{i, j}-B_{i}\left|\hat{\lambda}_{i, j}\right| / G_{i} \\
\hat{\lambda}_{i, j} \quad G_{i}=0
\end{array} G_{i}>0\right.
\end{array}\right.
$$




\section{References}

[1] Allen D.E. and Tan M.L. (1999), A Test of the Persistence in the Performance of UK Managed Funds, Journal of Business Finance and Accounting, 25, pp. 559-593.

[2] Amenc N. and Le Sourd V. (2005), Rating the Ratings, EDHEC Publication.

[3] Anderson T.W. and L.A. Goodman (1957), Statistical Inference about Markov Chains, Annals of Mathematicals Statistics, 28, pp. 89-110.

[4] Barras L., Scaillet O. and Wermers R. (2010), False Discoveries in Mutual Fund Performance: Measuring Luck in Estimated Alphas, Journal of Finance, 65(1), pp. 179-216.

[5] Berk J. and Green R. (2004), Mutual Fund Flows and Performance in Rational Markets, Journal of Political Economy, 112, pp. 1269-1295.

[6] Bhattacharya S., Dasgupta A., Guembel A. and Prat A. (2008), Incentives in Funds Management: A Literature Overview, in Thakor A.V. and Boot A.W.A (eds), Handbook of financial intermediation and banking, Chapter 9, pp. 285-304.

[7] Blake C.A. and Morey M. (2000), Morningstar Ratings and Mutual Fund Performance, Journal of Financial and Quantitative Analysis, 35, pp. 451-483.

[8] Blake C.R., Elton E.J. and Gruber M.J. (1993), The Performance of Bond Mutual Funds, Journal of Business, 66(3), pp. 371-403.

[9] Blake D. and Timmermann A. (1998), Mutual Fund Performance: Evidence for the UK, European Finance Review, 2, pp. 57-77.

[10] Bollen N. and Busse J. (2004), Short-term Persistence in Mutual Fund Performance, Review of Financial Studies, 18, pp. 569-597.

[11] Brown K., Harlow W.V. and Starks L. (1996), Of Tournaments and Temptations: An Analysis of Managerial Incentives in the Mutual Fund Industry, Journal of Finance, 51(1), pp. 85-110.

[12] Brown S. and Goetzmann W. (1995), Performance persistence, Journal of Finance, 50, pp. 679-698.

[13] Brown S., Goetzmann W., Ibbotson R. and Ross S. (1992), Survivorship Bias in Performance Studies, Review of Financial Studies, 5, pp. 553-580.

[14] Budiono D.P. and Martens M. (2009), Persistence in Mutual Fund Performance and Time-Varying Risk Exposures, Working Paper, SSRN.

[15] Carhart M.M. (1997), On Persistence in Mutual Fund Performance, Journal of Finance, $52(1)$, pp. 57-82.

[16] Chen J., Hong H., Huang M. and Kubik J. (2004), Does Fund Size Erode Performance? Liquidity, Organizational Diseconomies, and Active Money Management, American Economic Review, 94, pp. 1276-1302.

[17] Chevalier J. and Ellison G. (1997), Risk taking by Mutual Funds as a Response to Incentives, Journal of Political Economy, 105, pp. 1167-1200.

[18] Chevalier J. and Ellison G. (1999), Are Some Mutual Fund Managers Better than Others? Cross-Sectional Patterns in Behavior and Performance, Journal of Finance, 54, pp. 875-899. 
[19] Cicotello C. and Grant C. (1996), Equity Fund Size and Growth: Implications for Performance and Selection, Financial Services Review, 5(1), pp. 1-12.

[20] Coval J. and Moskowitz T. (1999), Home Bias at Home: Local Equity Preference in Domestic Portfolios, Journal of Finance, 54, pp.1-39.

[21] Cuthbertson K., Nitzsche D. and O'Sullivan N. (2008), UK Mutual Fund Performance: Skill or Luck?, Journal of Empirical Finance, 15(4), pp. 613-634.

[22] Darolles S. and Gouriéroux C., The Effects of Management and Provision Accounts on Hedge Fund Returns, Working Paper, 2009.

[23] Detzler M.L. (1999), The Performance of Global Bond Mutual Funds, Journal of Banking and Finance, 23, pp. 1195-1217.

[24] Edelen R.M. (1999), Investor Flows and the Assessed Performance of Open-End Mutual Funds, Journal of Financial Economics, 53, pp. 439-466.

[25] Elton E.J., Gruber M.J. and Blake C.R. (1996a), The Persistence of risk-adjusted Mutual Fund Performance, Journal of Business, 69, pp. 133-157.

[26] Elton E.J., Gruber M.J. and Blake C.R. (1996b), Survivorship Bias and Mutual Fund Performance, Review of Financial Studies, 9(4), pp. 1097-1120.

[27] Elton E.J., Gruber M.J. and Blake C.R. (2001), A first Look at the Accuracy of CRSP Mutual Fund Database and a Comparison of the CRSP and Morningstar Mutual Fund Database, Journal of Finance, 56, pp. 2415-2430.

[28] Elton E.J., Gruber M.J. and Blake C.R. (2003), Incentive Fees and Mutual Funds, Journal of Finance, 58(2), pp. 779-804.

[29] Elton E.J., Gruber M.J., Das S. and Hlavka M. (1993), Efficiency with Costly Information: A Reinterpretation of Evidence from Managed Portfolios, Review of Financial Studies, 6(1), pp. 1-22.

[30] Fama E.F. and French K.R. (1992), The Cross-Section of Expected Stock Returns, Journal of Finance, 47(2), pp. 427-65.

[31] Fama E.F. and French K.R. (1993), Common Risk Factors in the Returns on Stocks and Bonds, Journal of Financial Economics, 33(1), pp. 3-56.

[32] Fama E.F. and French K.R. (2004), The Capital Asset Pricing Model: Theory and Evidence, Journal of Economic Perspectives, 18(3), pp. 25-46.

[33] Ferson W.E. and Schadt R.W. (1996), Measuring Fund Strategy and Performance in Changing Economic Conditions, Journal of Finance, 51, pp. 425-62.

[34] Fletcher J. and Forbes D. (2002), An Exploration of the Persistence of UK Unit Trusts Performance, Journal of Empirical Finance, 9, pp. 475-493.

[35] Garnier O. and Pujol T. (2007), Can today's Stars be used to read the Stars of the Future?, Les Cahiers Scientifiques de l'AMF, 3, March.

[36] Goetzmann W. and Ibbotson R. (1994), Do Winners Repeat? Patterns in Mutual Fund Performance, Journal of Portfolio Management, 20, pp. 9-18.

[37] Golub G.H. and Van Loan C.F. (1989), Matrix Computations, John Hopkins University Press, London. 
[38] Grinblatt M. and Keloharju M. (2000), The Investment Behavior and Performance of Various Investor-types: A Study of Finland's Unique Data Set, Journal of Financial Economics, 55, pp. 43-67.

[39] Grinblatt M. and Titman S. (1989a), Portfolio Performance Evaluation: Old Issues and New Insights, Review of Financial Studies, 2(3), pp. 396-422.

[40] Grinblatt M. and Titman S. (1989b), Mutual Fund Performance: An Analysis of Quarterly Portfolio Holdings, Journal of Business, 62, pp. 393-416.

[41] Grinblatt M. and Titman S. (1992), The Persistence of Mutual Fund Performance, Journal of Finance, 47, pp. 1977-1984.

[42] Gruber M.J. (1996), Another Puzzle: The Growth in Actively Managed Funds, Journal of Finance, 51, pp. 783-810.

[43] Hendricks D., Patel J. and Zechhauser R. (1993), Hot Hands in Mutual Funds: Short-Run Persistence of Relative Performance, Journal of Finance, 48, pp. 93-130.

[44] Huij J. and Derwall J. (2008), Hot Hands in Bond Funds or Persistence in Bond Performance, Journal of Banking and Finance, 32, pp. 559-572.

[45] Huij J., Martens M. and Post T. (2007) Return Persistence, Risk Dynamics and Momentum Exposures of Equity and Bond Mutual Funds, Working Paper, SSRN.

[46] Indro D., Jiang C., Hu M. and Lee W. (1999), Mutual Fund Performance: Does Fund Size Matter?, Financial Analysts Journal, 55, pp. 74-87.

[47] Israel R.B., Rosenthal J.S. and Wei J.Z. (2001), Finding Generators for Markov Chains via Empirical Transition Matrices with Applications to Credit Ratings, Mathematical Finance, 11, pp. 245-265.

[48] Jegadeesh N. and Titman S. (1993), Returns to Buying Winners and Selling Losers: Implications for Stock Market Efficiency, Journal of finance, 48(1), pp. 65-91.

[49] Jensen M. (1968), The Performance of Mutual Funds in the Period 1945-1964, Journal of Finance, 23(2), pp. 389-416.

[50] Kacperczyk M.T., Sialm C. and Lu Zheng L. (2005), On the Industry Concentration of Actively Managed Equity Mutual Funds, Journal of Finance, 60(4), pp. 1983-2011.

[51] Kang J-K. and Stulz R. (1997), Why is there a Home Bias? An Analysis of Foreign Portfolio Equity ownership in Japan, Journal of Financial Economics, 46, pp. 3-28.

[52] Kavvathas D. (1999), Estimating Credit Rating Transition Probabilities for Corporate Bonds, University of Chicago, Working Paper.

[53] Kosowski R., Timmermann A., Wermers R. and White H. (2006), Can Mutual Fund "Stars" Really Pick Stocks? New Evidence from a Bootstrap Analysis, Journal of Finance, 61, pp. 2551-2596.

[54] Lehmann B.N. and Modest D.M. (1987), Mutual Fund Performance Evaluation: A Comparison of Benchmarks and a Benchmark of Comparisons, Journal of Finance, 42(2), pp. 233-265.

[55] Lintner J. (1965), The Valuation of Risk Assets and the Selection of Risky Investments in Stock Portfolios and Capital Budgets, Review of Economics and Statistics, 47(1), pp. $13-37$. 
[56] Malkiel B.G. (1995), Returns from Investing in Equity Mutual Funds 1971 to 1991, Journal of Finance, 50(2), pp. 549-572.

[57] Mamaysky H., Spiegel M. and Zhang H. (2007), Improved Forecasting of Mutual Fund Alphas and Betas, Review of Finance, 11(3), pp. 359-400.

[58] Morningstar, The Morningstar Rating Methodology, Morningstar Methodology, March 2005.

[59] Nanda V., Wang J. and Zheng L. (2004), Family Values and the Star Phenomenon: Strategies of Mutual Fund Families, Review of Financial Studies, 17, pp. 667-698.

[60] Otten R. and Bams D. (2007), The Performance of Local versus Foreign Mutual Fund Managers, European Financial Management, 13(4), pp.702-720.

[61] Sharpe W.F. (1964), Capital Asset Prices: A Theory of Market Equilibrium under Conditions of Risk, Journal of Finance, 19(3), pp. 425-42.

[62] Sharpe W.F. (1966), Mutual Fund Performance, Journal of Business, 39, pp. 119-138.

[63] Sharpe W.F. (1992), Asset Allocation Management Style and Performance Measurement, Journal of Portfolio Management, December, pp. 7-19.

[64] Shukla R. and van Inwegen G. (1995), Do Locals Perform Better than Foreigners? An Analysis of UK and US Mutual Fund Managers, Journal of Economics and Business, 47, pp. 241-54.

[65] Starks L. (1987), Performance Incentive Fees: An Agency Theoretic Approach, Journal of Financial and Quantitative Analysis, 22(1), pp. 17-32.

[66] Treynor J.L. (1965), How to Rate Management of Investment Funds, Harvard Business Review, 43, pp. 63-75. 